\title{
A "tandem approach" using sequential diagnostic (ultraslim) and therapeutic (standard size) direct freehand cholangioscopy to guide mechanical lithotripsy of a giant cystic duct remnant stone
}

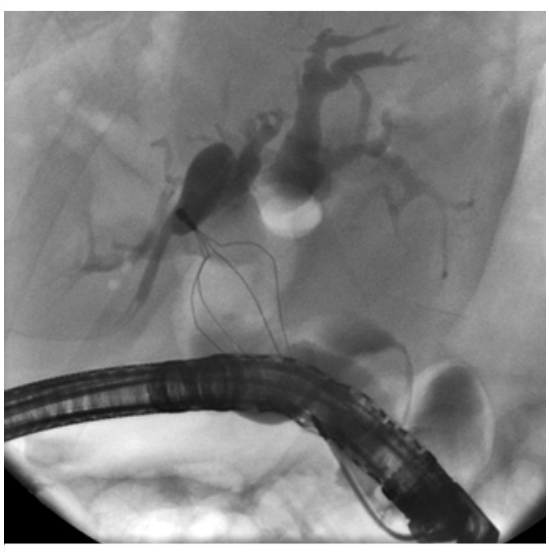

-Fig. 1 Endoscopic retrograde cholangiography (ERC) image (mixed spontaneous air and dye cholangiogram) in the long axis provides limited information because of reduced maneuverability owing to a deep papilla location at the 3 o'clock position of a periampullary diverticulum. A large stone ( $25 \mathrm{~mm}$ in diameter) is seen, but its position is equivocal because of an overlying grossly dilated low-inserting cystic duct remnant.

This is the case of an 85-year-old woman with a distant history of cholecystectomy and complicated bile duct stone disease who had undergone several endoscopic retrograde cholangiography (ERC) procedures including standard-incision papillotomy elsewhere, and was now undergoing repeat ERC after resolution of an episode of acute cholangitis. Because of a complicated ERC anatomy, fluoroscopy provided limited information as to the location of the stone; basket capture was unsuccessful ( $\triangleright$ Fig. 1).

With the patient still receiving piperacillin/tazobactam antibiotic treatment, we therefore proceeded to diagnostic direct cholangioscopy after freehand intubation using an ultraslim endoscope (GIF XP160; Olympus, Hamburg, Germany; outer diameter $5.9 \mathrm{~mm}$, working channel $2.0 \mathrm{~mm}$ ) [1], unequivocally identifying a cystic duct remnant stone, which was confirmed by cholangioscopy-directed
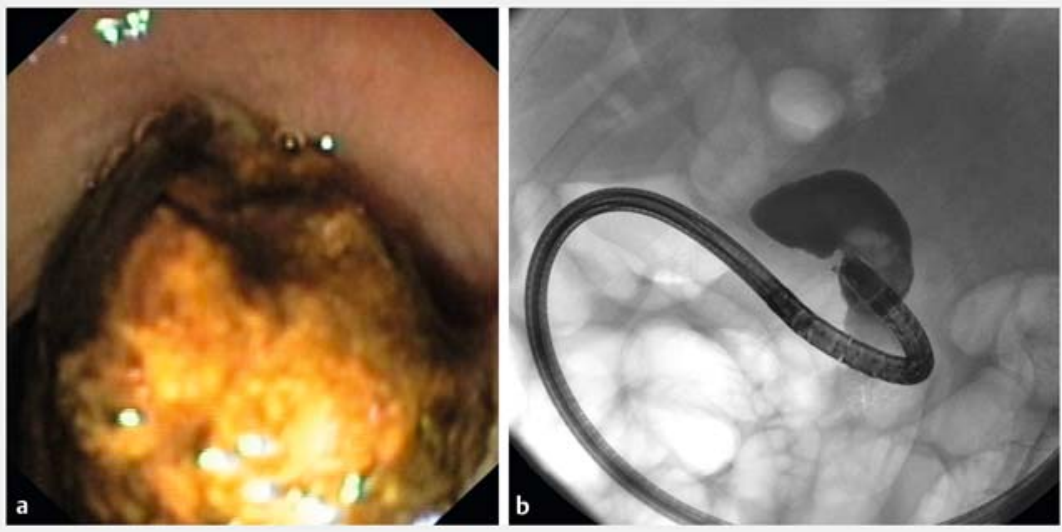

- Fig. 2 Direct cholangioscopy was performed using an ultraslim upper gastrointestinal endoscope (note: neither $\mathrm{CO}_{2}$ insufflation nor saline instillation was needed, given the markedly dilated biliary system). a Direct cholangioscopy view showing a stone in the cystic duct remnant. b Fluoroscopic image after cholangioscopy-guided contrast injection confirming the stone to be located in the hugely dilated cystic duct remnant.

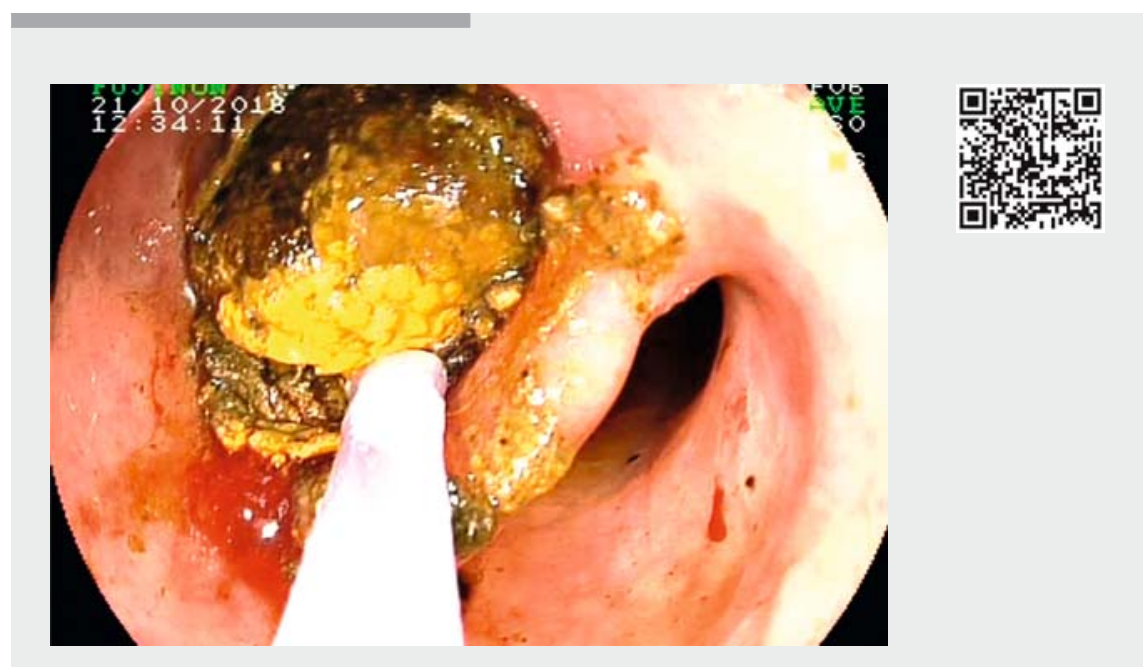

Video 1: In light of equivocal findings on endoscopic retrograde cholangiography (ERC), we first performed diagnostic (ultraslim) direct cholangioscopy in freehand fashion to identify a giant stone in the markedly dilated cystic duct remnant, and subsequently used balloon dilation-assisted therapeutic (standard size) direct cholangioscopy with cholangioscopy-facilitated mechanical lithotripsy to complete stone clearance.

injection of contrast media ( $>$ Fig. 2 ). Biliary insertion of a standard-sized upper gastrointestinal endoscope was precluded because of an insufficiently large papillotomy opening; therefore, endoscopic papillary large balloon dilation (EPLBD; CRE Balloon Dilation Catheter, 

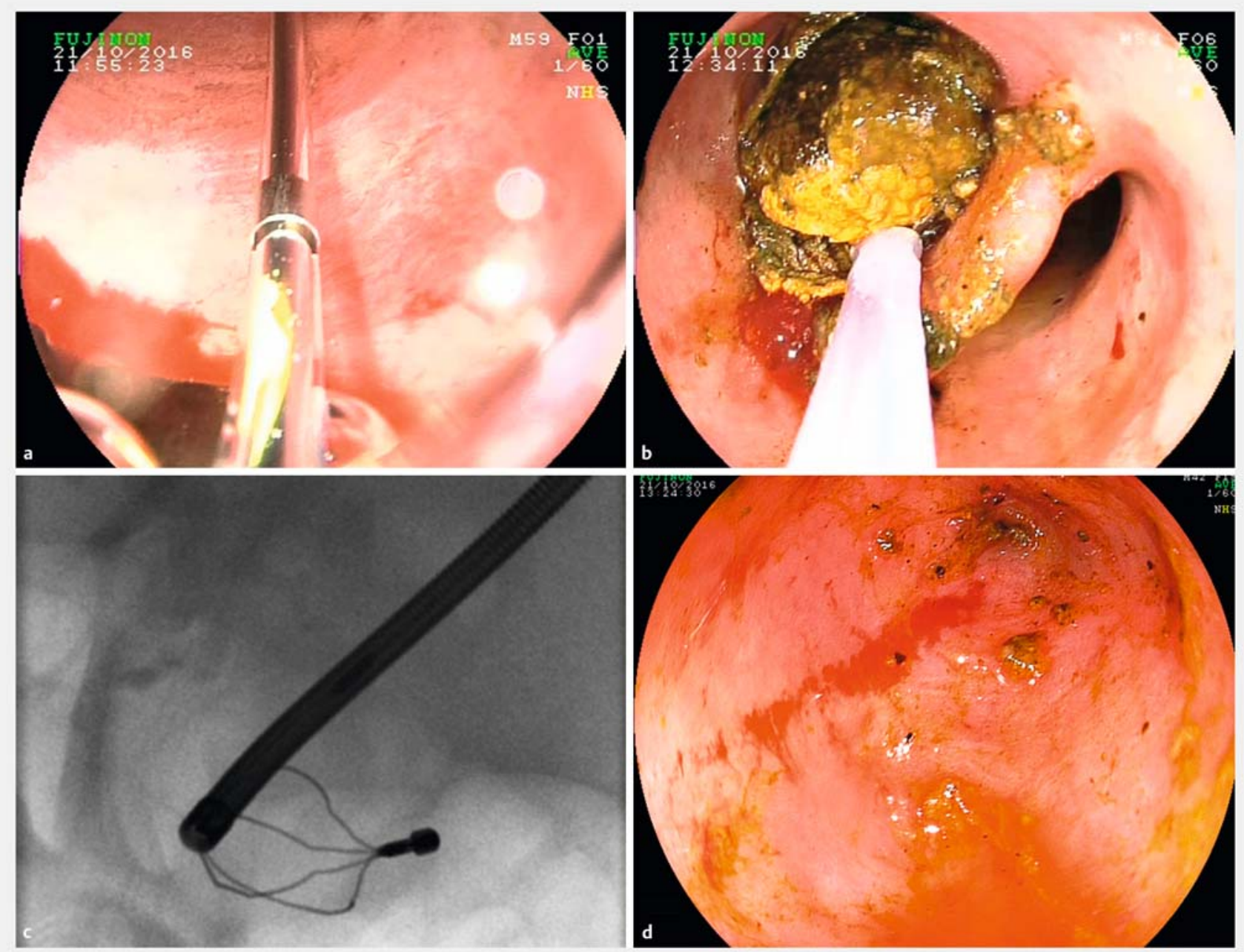

- Fig. 3 The subsequent stages of the tandem procedure. a Endoscopic papillary large balloon dilation (EPLBD) up to $18 \mathrm{~mm}$ was performed under prograde endoscopic visualization. b Direct cholangioscopy-directed basket capture was performed using standard endoscopic retrograde cholangiography (ERC) equipment. c Fluoroscopy was used to guide mechanical lithotripsy as the metal sheath diameter surpassed the diameter of the endoscope's working channel. $\mathbf{d}$ Complete stone clearance up to the tip of the cystic duct remnant was confirmed by cholangioscopy after the mechanical lithotripsy fragments had been extracted by a basket and/or Roth net under direct cholangioscopic visualization.

Boston Scientific, Ratingen, Germany) was performed ( $\triangleright$ Fig. 3 a).

EPLBD-assisted therapeutic (standard size) direct cholangioscopy was likewise performed freehand using a Fujinon EG590WR (Fujifilm, Düsseldorf, Germany; outer diameter $9.6 \mathrm{~mm}$, working channel $2.8 \mathrm{~mm}$ ) and was followed by cholangioscopy-guided stone capture using standard ERC equipment ( $\triangleright$ Fig. $\mathbf{3 b}$ ). The metal sheath, which exceeded the diameter of the working channel, was introduced after the external plastic sheath had been cut and the scope had been removed; mechanical lithotripsy was then performed under fluoroscopic control ( $\vee$ Fig. $3 \mathbf{c}$ ). Thereafter, the cystic duct remnant was completely cleared of mechanical lithotripsy fragments under direct cholangioscopic vision ( $\triangleright$ Fig. $\mathbf{3 d}$ ). In contrast to indirect visualization of the biliary system, for example by fluoroscopy-based ERC, direct cholangioscopy has advantages in both diagnosis and interventional potential in biliary diseases, and provides high quality imaging with a large field of view [2]. Here, we have presented a novel endoscopic technique for direct cholangioscopy-guided management of complex gall stone disease in a specifically committed endoscopy service. Cholangioscopy-guided mechanical lithotripsy of complex stone disease in the cystic duct stump is a novel innovative approach that integrates new and old endoscopic technology with widespread availability, contrary to catheter-based approaches, such as electrohydraulic or laser lithotripsy, with limited dissemination [3]. This novel, highly innovative concept of a "tandem approach," sequentially using diagnostic (ultraslim) followed by therapeutic (standard size) direct cholangioscopy, may streamline complex biliary interventions in selected cases in the future.

Endoscopy_UCTN_Code_TTT_1AR_2AK 


\section{Competing interests}

\section{None}

The Authors

\section{Vincent Zimmer ${ }^{1,2}$, Frank Lammert ${ }^{2}$}

1 Department of Medicine, Marienhausklinik St. Josef Kohlhof, Neunkirchen, Germany

2 Department of Medicine II, Saarland University Medical Center, Saarland University, Homburg, Germany

\section{Corresponding author}

\section{Vincent Zimmer, MD}

Department of Medicine, Marienhausklinik St. Josef Kohlhof, 66539 Neunkirchen, Germany

Fax: +49-6821-3632624

vincent.zimmer@gmx.de

\section{References}

[1] Brauer BC, Chen YK, Shah R]. Single-step direct cholangioscopy by freehand intubation using standard endoscopes for diagnosis and therapy of biliary diseases. Am J Gastroenterol 2012; 107: 1030-1035
[2] Komanduri S, Thosani N, Abu Dayyeh BK et al. Cholangiopancreatoscopy. Gastrointest Endosc 2016; 84: 209-221

[3] Forbes N, Ishikawa T, Mohamed R. High resolution cholangioscopic electrohydraulic lithotripsy for fragmentation and extraction of impacted cystic duct stones. Endoscopy 2016; 48 (Suppl. 01): E88 -E89

\section{Bibliography}

DOI https://doi.org/10.1055/s-0043-106892

Endoscopy 2017; 49: E160-E162

(c) Georg Thieme Verlag KG

Stuttgart · New York

ISSN 0013-726X

\section{ENDOSCOPY E-VIDEOS}

https://eref.thieme.de/e-videos

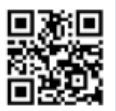

Endoscopy E-Videos is a free access online section, reporting on interesting cases and new techniques in gastroenterologica endoscopy. All papers include a high quality video and all contributions are freely accessible online.

This section has its own submission website at https://mc.manuscriptcentral.com/e-videos 